\title{
Photodiodes for Terahertz Applications
}

\author{
James P. Seddon, Michele Natrella, Xiaoli Lin, Chris Graham, Cyril Renaud Senior Member, IEEE \\ and Alwyn J. Seeds Life Fellow, IEEE
}

(Invited Paper)

\begin{abstract}
Terahertz generation using high-speed photodiodes has found commercial application in many areas ranging across spectroscopy, imaging and communications. In this paper we discuss the optimization of high-speed photodiodes in terms of bandwidth and output power. We identify some of the main limitations in the generation of high output power in the Terahertz frequency band. We present a modelling tool for the numerical evaluation of antenna coupled uni-travelling carrier photodiodes and experimental evaluation of the fabricated designs. We also present a thermal analysis of the photodiodes alongside pulsed measurements of the output power saturation.
\end{abstract}

Index Terms - THz photomixing, THz antennas, high-speed photodiodes, UTC-Photodiodes, Terahertz Radiation

\section{INTRODUCTION}

$\mathrm{T}$ HE terahertz (THz) region of the electromagnetic spectrum (0.1-10 THz)[1] has been a subject of interest from researchers due to a large range of potential applications, ranging from biomedical imaging and pharmaceutical quality control to next generation high-speed wireless communications[2].

However, due to a range of technological challenges in the generation and detection of $\mathrm{THz}$ radiation, fewer technologically mature solutions are available to fully exploit this potential. There have been several proposed technological solutions for generation of $\mathrm{THz}$ radiation, for example, Schottky diode multiplier chains[3], CMOS based transistors[4]-[6], Gunn diodes[7], IMPATT diodes, quantum cascade lasers[8][9], photoconductive switches[10]-[12] and high-speed photodiodes[13]-[15]. Key THz applications such as spectroscopy[16], imaging[17][18], metrology[19] and communications[20] impose differing sets of requirements on the $\mathrm{THz}$ source and detector. For example, THz spectroscopy and metrology require a wide bandwidth tunable source with a spectral linewidth narrow enough to resolve spectral features of interest and a high enough power level to pass through a sample under test and be detected[21].

For communications and imaging applications there are less stringent requirements on frequency tuneability of the source, but a stronger emphasis on the output power level. Of the $\mathrm{THz}$ sources discussed previously, coherent photonics-based sources can fulfil many of the requirements of tuneability and frequency stability along with high spectral resolution. One of the areas where photo-mixing sources underperform is output power

\footnotetext{
${ }^{\mathrm{T}}$ his work was supported by the Engineering and Physical Sciences Research Council (EPSRC) through the COTS Programme Grant (EP/J017671/1) and Hyperterahertz Programme Grant (EP/PO21859/1) The authors are with the
}

level, when compared to electronic room temperature sources, such as Schottky diodes and CMOS sources which generate milliwatt level power at $300 \mathrm{GHz}$. In this article we will explore what the main challenges in generating high output power in photodiodes are and some potential solutions to overcome this limitation.

The most widely developed photonics-based source, particularly for time-domain spectroscopy(TDS)[22], is based on low temperature grown gallium arsenide (LT-GaAs) which makes use of femtosecond pulses from a mode locked laser to generate ultrafast $\mathrm{THz}$ pulses. Time-domain spectroscopy however does have limitations arising from the costs of the ultra-fast pulsed laser drive systems, which operate at $\sim 800 \mathrm{~nm}$. The spectral resolution achievable is also limited primarily by the physical length of the optical delay line[23]. TDS systems based on $1550 \mathrm{~nm}$ pulsed fibre lasers have also been developed as a commercial solution making use of LT-InGaAs[24] and InAlAs/InGaAs heterostructures[25].

Continuous wave $(\mathrm{CW})$ generation of $\mathrm{THz}$ radiation can also be achieved by difference frequency photo-mixing in LTGaAs[26]-[29] and LT-InGaAs[30]-[32] or in high-speed InGaAs photodiodes[33]. In the case of LT-InGaAs and photodiodes the operating wavelength is within the $1550 \mathrm{~nm}$ telecommunications wavelength band. Operation in the telecommunications band has the advantage of the availability of a very wide selection of low cost, off the shelf photonic components and low loss transmission through standard optical fibres.

To generate $\mathrm{CW} \mathrm{THz}$ in a photoconductor or photodiode, two laser tones are combined to produce a heterodyne beat note at the difference frequency between the laser tones. Two major factors influence the frequency response of photodiodes. The photodiode resistance capacitance (RC) time constant arising from the product of the junction capacitance and load and series resistances and a time constant due to the finite transit time of the photogenerated carriers across the absorption and depletion region[14]. For p-i-n photodiodes the transit time response is dominated by low-velocity hole transport.

The Uni-Travelling Carrier photodiode (UTC-PD) photoresponse is dominated by electron transport[14], [15], [34]. In this device the absorber layer is p doped to a quasi-neutral level making holes the majority carrier which respond within the dielectric relaxation time through collective motion. The transit time response is then primarily limited by the electron transport

${ }^{1}$ Department of Electronic and Electrical Engineering, University College London, London, WC1E 7JE, U.K. (e-mail: james.seddon@ucl.ac.uk, a.seeds@ucl.ac.uk) 
TABLE I: SATURATED POWER LITERATURE SURVEY OF PHOTODIODE BASED THZ EMITTERS

\begin{tabular}{ccccc}
\hline \hline $\begin{array}{c}\text { Device } \\
\text { Type }\end{array}$ & $\begin{array}{c}\text { Coupling } \\
\text { Type }\end{array}$ & $\begin{array}{c}\text { Frequency } \\
(\mathrm{GHz})\end{array}$ & $\begin{array}{c}\text { Saturated } \\
\text { Power } \\
(\mathrm{dBm})\end{array}$ & Reference \\
\hline UTC-PD & Probe & 100 & 11.17 & {$[54]$} \\
UTC-PD & Probe & 110 & 10 & {$[36]$} \\
M-UTC- & Probe & 120 & 5 & {$[48]$} \\
PD & & & & \\
UTC-PD & Probe & 120 & 12.3 & {$[55]$} \\
TW-UTC- & Probe & 200 & 0 & {$[42]$} \\
PD & & & & \\
p-i-n-PD & Antenna & 200 & -14.4 & {$[37]$} \\
LT-GaAs & Probe & 252 & 2.55 & {$[29]$} \\
UTC-PD & Probe & 300 & -1.25 & {$[35]$} \\
UTC-PD & Waveguide & 350 & -2.68 & {$[51]$} \\
TW-UTC- & Antenna & 457 & -8.3 & {$[57]$} \\
PD & & & & \\
UTC-PD & Antenna & 500 & -17.7 & {$[56]$} \\
p-i-n PD & Antenna & 500 & -19 & {$[37]$} \\
UTC-PD & Antenna & 700 & -15.5 & {$[59]$} \\
TW-UTC- & Antenna & 912 & -16 & {$[57]$} \\
PD & & & & \\
p-i-n PD & Antenna & 1000 & -28.5 & {$[37]$} \\
UTC-PD & Antenna & 1005 & -19.63 & {$[60]$} \\
UTC-PD & Antenna & 1250 & -24.56 & {$[59]$} \\
TW-UTC- & Antenna & 1500 & -33 & {$[42]$} \\
PD & & & & \\
UTC-PD & Antenna & 1500 & -29.59 & {$[60]$} \\
UTC-PD & Antenna & 2000 & -40 & {$[59]$} \\
\end{tabular}

through the absorption and carrier collection layer[14] where in the collector layer electrons exhibit a velocity overshoot. In the absorption layer the electrons travel by drift/diffusion, the transport speed can be increased through the introduction of a quasi-field in the absorber by means of a graded doping profile[14].

While the UTC-PD structure removes the limitations of hole transport on the frequency response of the diode, a tradeoff still exists between the transit time through the absorption layer and optical responsivity. For vertically illuminated photodiodes a thick absorption layer is required for high responsivity. However, a thicker absorption layer is detrimental to the transit time response of the diode[14][34].

Several research directions have emerged to address the bandwidth responsivity trade-off. One interesting solution is to create a photonic cavity around a thin absorption region through the use of a semi-transparent top contact and metallic mirror to increase the interaction length with the absorbing material[35]. Using this structure output powers of $750 \mu \mathrm{W}$ at $300 \mathrm{GHz}$ were recorded with an absorption layer thickness of $150 \mathrm{~nm}$ and $3 \times 3$ $\mu \mathrm{m}^{2}$ active area.

Another approach is to utilize a waveguide integrated photodiode so that the carrier transport and optical absorption are now perpendicular to each other. In a waveguide integrated photodiode[36]-[39] light is evanescently coupled from a passive optical waveguide to an active absorbing waveguide or directly injected to the active area. However, care is still needed to keep the active area of the device small, so the junction capacitance is low. So called travelling wave photodiodes[40], [41] distribute the junction capacitance along the length of an extended device (50 $\mu \mathrm{m}$ in [42] for a Travelling Wave UTC-PD (TW-UTC-PD)).

The power generation in a travelling wave photodiode is maximized when the group velocity of the optical signal is matched to the phase velocity of the generated $\mathrm{THz}$ signal[41]. In the case where the rear terminal of the waveguide is left as an open circuit, interference can occur due to the reflected backwards propagating waves. This can be reduced by appropriately terminating the rear terminal with a matched impedance. UTC-PDs also exhibit higher output saturation current compared to $\mathrm{p}$-i-n photodiodes[34]. In $\mathrm{p}$-i-n photodiodes, high optical excitation in the intrinsic absorption layer leads to an accumulation of carriers in the depletion region causing the field to collapse; the lower carrier velocity of holes is the primary source of carrier accumulation resulting in saturation of the device and compression of the output RF power. Due to the increased electron velocity in the UTC-PD collection layer the saturation threshold is increased by an order of magnitude[43].

For high optical current operation there have been several demonstrations of high current high output power Modified UTC-PDs (M-UTC-PD). In these devices a lightly n-doped layer[44][45] is inserted between the collector and absorber layers to distort the field in order to compensate for the effects of accumulated space charge. The reported saturation currents for $20 \mu \mathrm{m}$ and $25 \mu \mathrm{m}$ diameter photodiodes was $90 \mathrm{~mA}$ and 120 $\mathrm{mA}$ respectively. Modifications to the absorber region have also been developed where an undoped InGaAs layer is added to the absorber region in order to improve the bandwidth responsivity tradeoff for vertically illuminated devices[46], [47]. Both the partially depleted absorber and cliff layers were added to modified waveguide UTC-PDs in [48] with output powers of 5 $\mathrm{dBm}$ at $120 \mathrm{GHz}$ being demonstrated and a $3 \mathrm{~dB}$ bandwidth of $75 \mathrm{GHz}$. A waveguide integrated modified UTC-PD was demonstrated in [49] with a $3 \mathrm{~dB}$ bandwidth of $105 \mathrm{GHz}$ for a $24 \mu \mathrm{m}^{2}$ active area. The device utilized an InGaAsP depletion layer for better evanescent coupling from the integrated waveguide to the absorber at the expense of a reduced carrier velocity. The maximum reported output power at $100 \mathrm{GHz}$ for the devices in [49] was $-4.4 \mathrm{dBm}$ at $100 \mathrm{GHz}$ with a photocurrent of $5.5 \mathrm{~mA}$. The larger active area devices $(50$ and $35 \mu \mathrm{m}^{2}$ ) reported powers of $2 \mathrm{dBm}$ and $-0.4 \mathrm{dBm}$ at $100 \mathrm{GHz}$

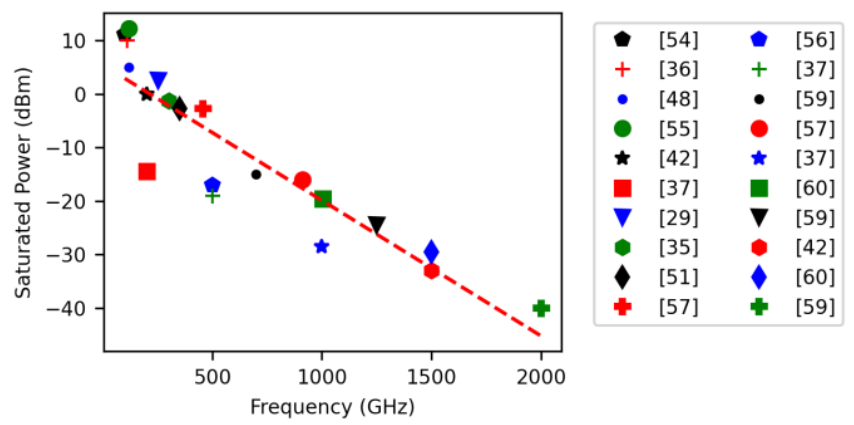

Fig. 1. Comparison of saturated output power for photodiodes from the literature.

respectively. Thermal failure resulted at the recorded maximum photocurrent for the smaller active area device. This 
demonstrates that despite compensating for space charge effects, performance degradation due to thermal effects still plays a significant role for small active area devices with higher $3 \mathrm{~dB}$ bandwidths. It is not clear for these devices, however, how much the influence of the reduced saturation velocity in the collector layer contributed to the lower saturation current.

The electronic circuitry integrated with photodiodes also plays an important role in maximizing the output power from photodiodes. UTC-PDs and p-i-n diodes have been integrated with rectangular waveguide modules[50] and integrated stub tuning circuits in order to maximize output power[13], [51][54], the integrated resonant stub tuning reaching a saturated output power of $17 \mathrm{~mW}$ at $120 \mathrm{GHz}$ [55].

Photodiodes have also been combined with planar integrated antenna structures, ranging from broadband bow-tie and log periodic antennas [37], [42], [56]-[58] to resonant slot antennas[57], [59], [60]. A comparison of the current state of the art in terms of saturated output power of $p-i-n$ and UTC photodiodes is shown in Figure 1 and detailed in Table I.

To increase total output power, arrays of individual photodiodes can be combined either using an on-chip waveguide power combiner or an array of integrated antenna elements. This has been demonstrated through the use of a Wilkinson power combiner in[61], [62], with a $1 \times 8$ bowtie antenna array integrated with UTC-PDs in [63]. A 1x4 array of M-UTC-PDs was demonstrated in [64] showing a decreasing $3 \mathrm{~dB}$ bandwidth as the number of array elements increased. This was reported as due to the increasing capacitance as more devices are added to the array. Steering of the emitted $\mathrm{THz}$ beam from a $4 \times 4$ array of antennas driven by a $1 \times 4$ array of UTC-PDs was demonstrated in [65]. The photodiode array was driven by an optical phased array circuit based on silica waveguides.

In summary we have investigated output power as a common key factor in applications of $\mathrm{THz}$ radiation. There are several approaches to be taken in order to optimize the generated power from photodiode sources. A comprehensive review of epitaxial design is presented in [66]. In this paper we will cover optimization of impedance matching between the photodiode and integrated antennas and the effects of high power operation paying attention to thermal power dissipation[67], an issue that has been comparatively less explored[68].

\section{DEVICE IMPEDANCE MEASUREMENT AND MODELLING}

To achieve maximum power transfer from a source to a load the impedances of the source and load should be matched. For the case of a complex source impedance the load impedance should be equal to the complex conjugate of the source impedance. In order to assess the coupling efficiency of a photodiode to an integrated antenna, measurement of the complex impedance of the photodiode is required. Development of a suitable impedance model also aids in accurate simulation of the coupling efficiencies between the photodiode and antenna.

We have previously demonstrated an equivalent circuit model of the UTC-PD where the layer structure of the photodiode is accounted for by a series of parallel RC circuits building on the commonly used simplified circuit that accounts only for the device series resistance and junction capacitance[69], [70]. The additional RC parameters have a physical significance in the device as they account for the effects of the spacer layers inserted between the carrier collector layer and absorption layer to reduce the heterojunction band gap discontinuity. We have demonstrated in [71] that the simplified photodiode equivalent circuit is unable to achieve consistent agreement with the real and imaginary parts of the photodiode impedance. A schematic of the modified equivalent circuit model developed in [71] is shown in Figure 2 with the corresponding photodiode layer structure.

The impedance of the photodiode was measured using a performance network analyzer (PNA). A one port $S_{11}$ reflection coefficient measurement is carried out to obtain the device impedance. The circuit parameters are then tuned to fit the measured data. Some parameters such as the series resistance can be calculated from the semiconductor layer properties and the contact resistance of the device.

Knowledge of the impedance of the photodiode and an appropriate equivalent circuit model enables the numerical calculation of the absolute radiated power of antenna coupled devices as demonstrated in [72] and [73]. A narrow band matching circuit can also be designed using common coplanar waveguide circuit components such as capacitors and quarter wave stubs[55].

A full wave 3D model of the UTC-PD was created using CST Microwave Studio. Each RC parallel circuit from the equivalent

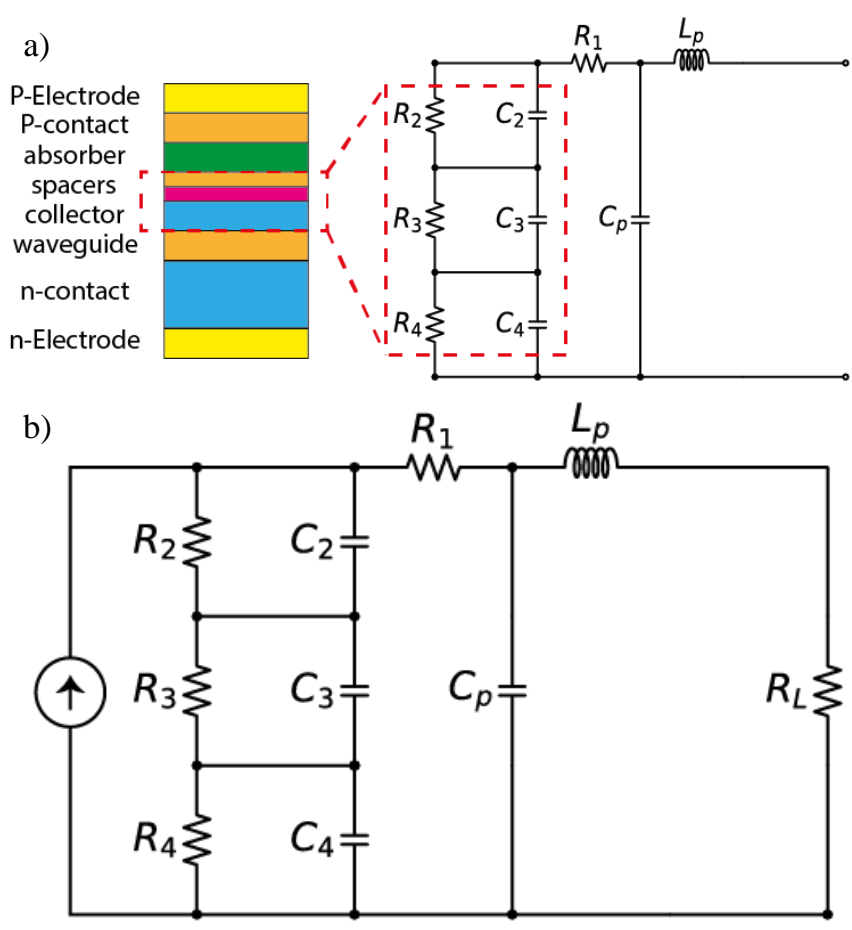

Fig. 2. a) Equivalent circuit impedance model with corresponding epitaxial layer structure. b) Equivalent circuit model for device photo response driven by an ideal current source with a $50 \Omega$ load impedance. 

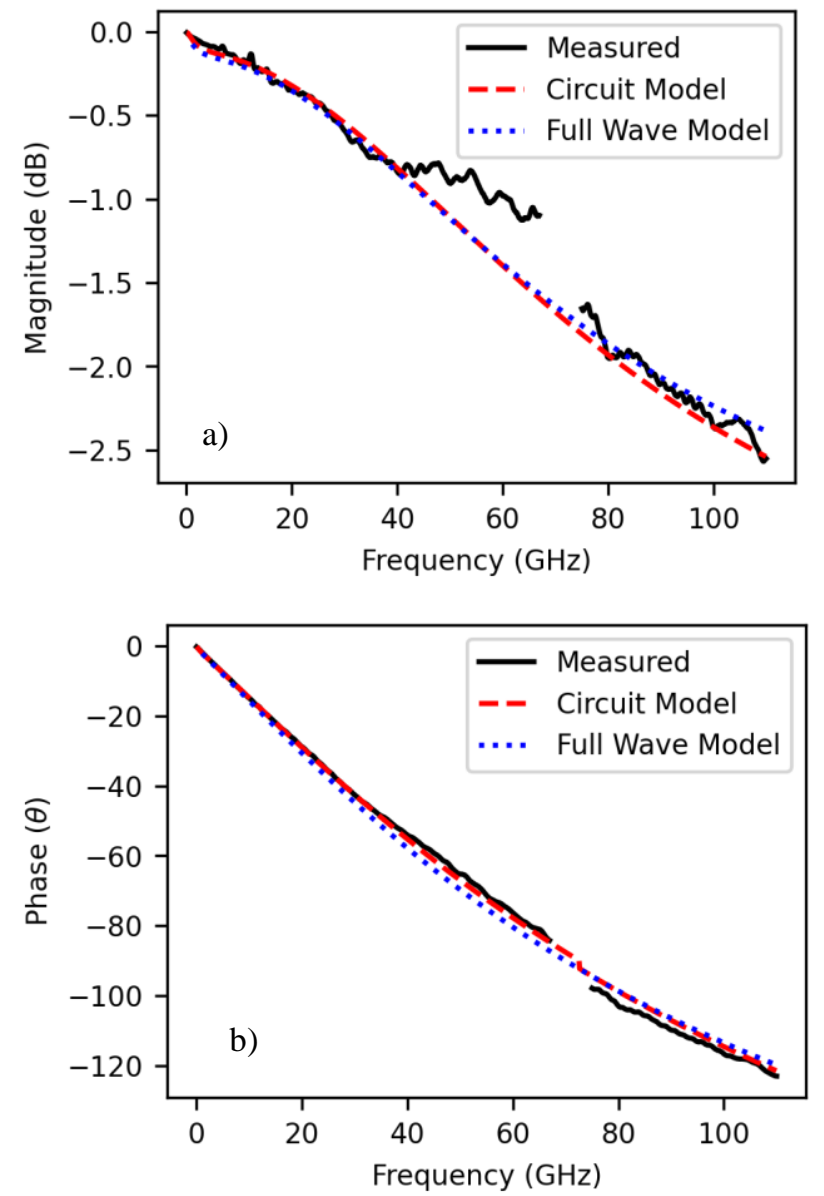

Fig. 3. $\mathrm{S}_{11}$ a) Magnitude and b) phase for a $3 \times 10 \mu \mathrm{m}^{2}$ active area UTC photodiode measured up to $67 \mathrm{GHz}$ using an Agilent PNA and from 75-110 GHz using VDI W band VNA extender modules.

circuit model is represented in CST as a block with appropriate conductivity and relative permittivity.

A $50 \Omega$ port is connected across the terminals of the photodiode model with ideal perfectly conducting wires which are kept short to avoid the introduction of spurious inductive reactance. The $S_{11}$ reflection coefficient of the full wave model and equivalent circuit model are shown in Figure 3 alongside the measured $S_{11}$. There is good agreement between the measured data and model data across both of the measured frequency bands. Crucially, there is simultaneous agreement between both the magnitude and phase data, which for the simplified circuit model was not possible. The frequency photoresponse of the UTC-PDs was measured using an Agilent Lightwave Component Analyzer (LCA). The maximum output optical power from the LCA is $6 \mathrm{dBm}$. The light from the LCA was coupled into the optical waveguide of the photodiode via a tapered lensed fibre with a spot size diameter of $2.5 \mu \mathrm{m}$. A polarization controller was placed before the lensed fibre to maximize the power coupled into the photodiode. The measured optical power before the lensed fibre was $5.68 \mathrm{dBm}$. Figure 4 shows the measured frequency photo-response for a $3 \times 10$ and a $3 \times 15 \mu \mathrm{m}^{2}$ UTC-PD.

From the model, the frequency response of the photodiode can be calculated also including the contributions of the transit
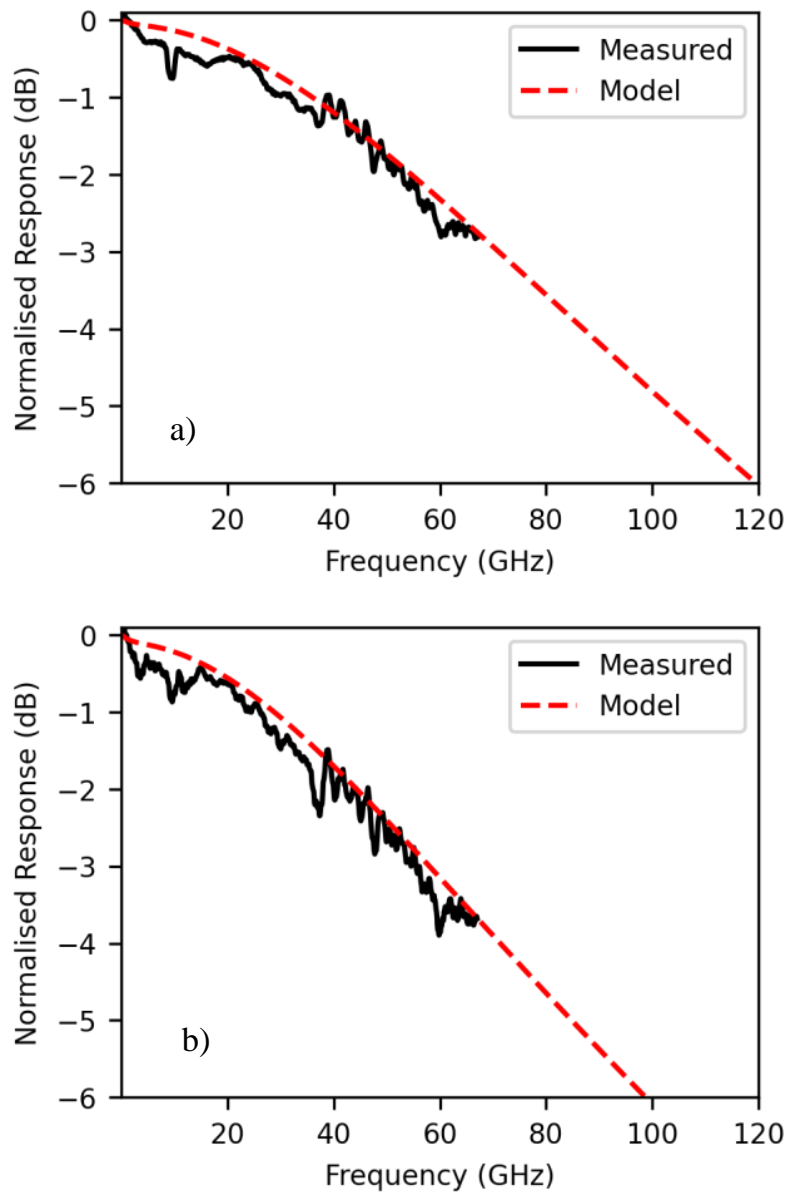

Fig. 4. $S_{21}$ Measured frequency response for a $3 \times 10 \mu \mathrm{m}^{2}$ a) and a $3 \times 15 \mu \mathrm{m}^{2}$ b) active area UTC-PD with $-2.5 \mathrm{~V}$ bias. The model data is calculated using the RC response equivalent circuit model from Figure 1 and scaled by the transit time response of the UTC-PD.

time response. An ideal current source is placed in parallel before the three RC circuits and the input port is terminated with a $50 \Omega$ load resistance as shown in Figure 2 b. The normalized transit time response is also calculated for a $20 \mathrm{mV}$ quasi-field in the absorber region following the process detailed in [71]. There is a good agreement between the calculated frequency photo-response of the photodiodes with the measured results. The $3 \mathrm{~dB}$ roll-off for the $3 \times 10 \mu \mathrm{m}^{2}$ device is shown to be around $71 \mathrm{GHz}$ from the model data while the $3 \times 15 \mu \mathrm{m}^{2}$ device is around $60 \mathrm{GHz}$. This is due to the larger active area of the $3 \times 15$ $\mu \mathrm{m}^{2}$ and hence larger junction capacitance. There is good agreement between the modelled frequency photo-response of the photodiode and the measured data after applying a correction for the transit time $-3 \mathrm{~dB}$ bandwidth of $270 \mathrm{GHz}$.

Using the full wave model, we can design suitable integrated planar antennas and estimate the total radiated power when combined with substrate integrated silicon lenses.

\section{INTEGRATED ANTENNA DESIGN AND MEASUREMENT}

Previous demonstrations of both UTC-PDs and p-i-n PDs integrated with planar antennas have taken two approaches. One approach is to make use of broadband antennas such as the 

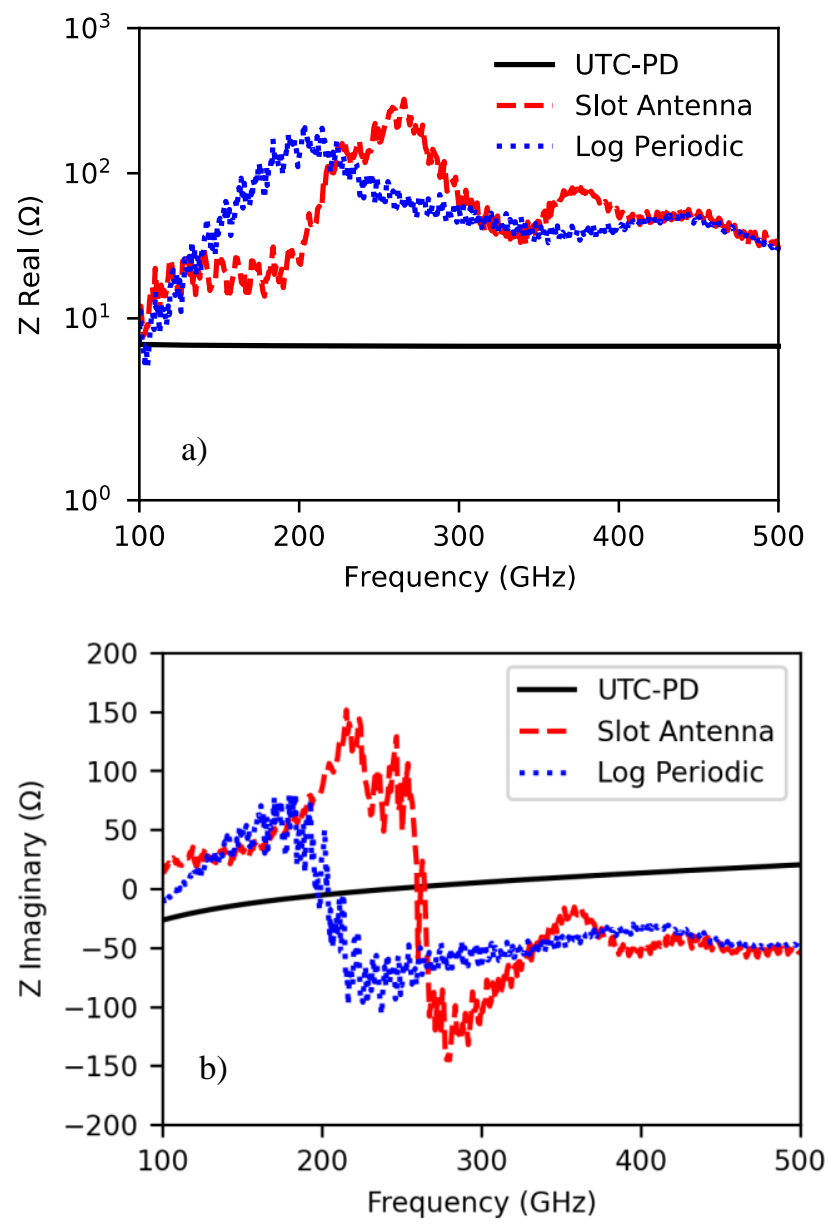

Fig. 5. Numerically calculated real and imaginary impedance for a $3 \times 15 \mu \mathrm{m}^{2}$ active area UTC photodiode, log periodic antenna and slot antenna.

logarithmic spiral antenna and log periodic antenna. The other is to make use of resonant antennas such as the half wave dipole and slot antenna. The broadband antennas mentioned earlier are typically described as having a constant real impedance over a wide frequency range. When considering a driving source such as the UTC-PD which has been shown to have a complex impedance with a strongly frequency dependent reactive part, broadband matching to a constant real antenna impedance is challenging. For applications such as spectroscopy where a wide frequency bandwidth is required to span several spectral lines, selection of an antenna that can deliver enough detectable power over the $\mathrm{THz}$ range is important. For cases where delivering maximum power over a smaller bandwidth is required, resonant slot antennas are a suitable solution. While the UTC-PD is essentially an ideal current source at DC, i.e., it exhibits a real and very high impedance, the impedance real part decreases significantly as the frequency of operation increases and tends to settle on values of the order of 5-10 $\Omega$, as shown in Figure 5 a). Consequently, there is likely to be a large amount of power not coupled to the antenna due to the substantial mismatch. To achieve maximum coupling efficiency in these cases a low impedance antenna conjugate matched to the UTCPD should be considered.

Using the full wave model discussed previously, we can evaluate the coupling efficiency and output power of UTC-PDs integrated with planar antennas. The impedance of an antenna structure mounted on a substrate integrated Silicon lens can also be numerically calculated. The substrate integrated silicon lens was pioneered by Rutledge[74] and has been used for both antenna integrated p-i-n PDs[37][75], UTC-PDs and photoconductive switches. Until recently the substrate integrated lens had only been modelled using a geometric optics approach. We have shown previously in [73], by means of full wave modelling, that the silicon lens has an impact on the device impedance and is very sensitive to misalignment of the device from the centre of the lens.

Two antenna designs have been evaluated, a resonant slot antenna shown in Figure 6 b) and a planar log periodic (LP) antenna shown in Figure $6 \mathrm{c}$ ). The resonant slot antenna impedance and UTC-PD impedance from the respective full wave models are shown in Figure 5. A resonance feature around $250 \mathrm{GHz}$ can be observed where the imaginary part of the antenna impedance crosses zero and the real part is over $300 \Omega$. The ripples in the antenna impedance are caused by the silicon lens which has been shown to act as a resonator due to the high refractive index of the silicon in contrast with the surrounding air[73][76]. The resonance effects can be addressed through the use of a suitable antireflective coating.

As mentioned earlier, resonant antennas driven with a complex low impedance source result in poor coupling efficiency due to the large mismatch between the source impedance and high resistive part of the antenna impedance. In order to maximize the coupled output power, the antenna impedance should be as close as possible to the complex conjugate of the source impedance.

This is the case around $100 \mathrm{GHz}$ where the impedance of the UTC-PD is 7.5-j20 and the impedance of the antenna is close to the complex conjugate of this value at $11.93+\mathrm{j} 21.37$.

The log periodic antenna impedance also has a resonance feature around $200 \mathrm{GHz}$. This results in a similar inductive
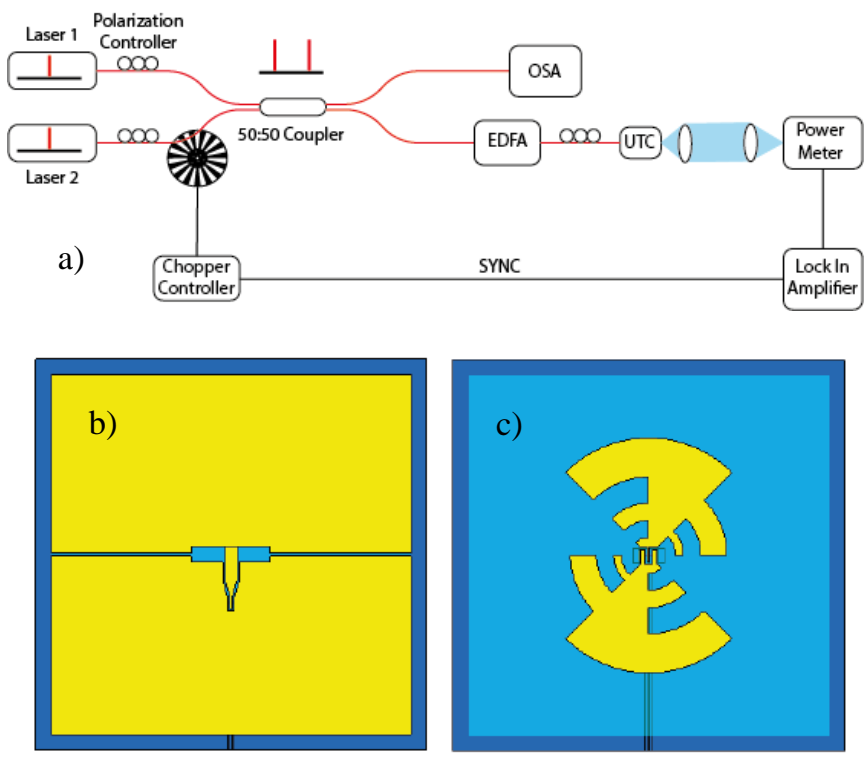

Fig. 6. Schematic diagram for antenna integrated UTC-PD output power measurements and illustrations of the two antenna types evaluated. 


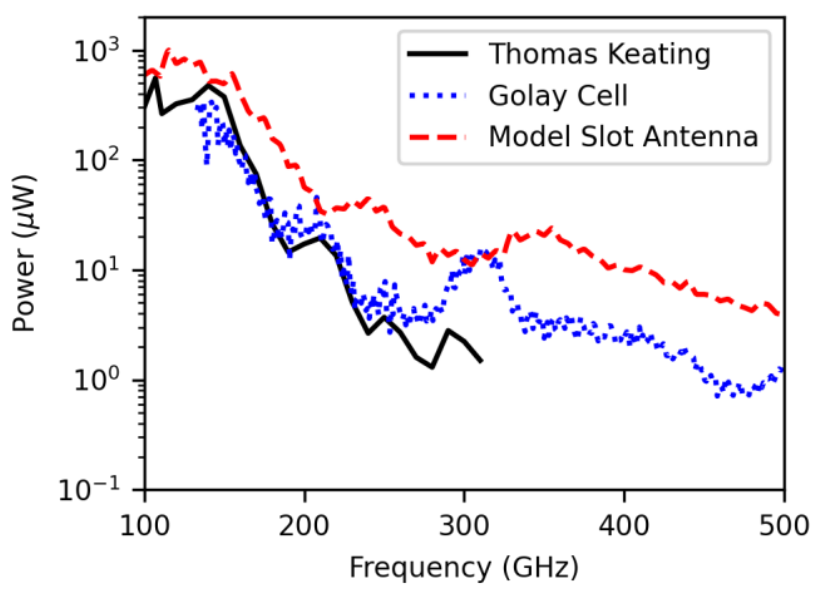

Fig. 7. Measured output power for the $3 \times 15 \mu \mathrm{m}^{2}$ UTC-PD integrated with a resonant slot antenna. Full wave modelling data, accounting for the transit time response and the solid angle of the of the TPX lens, is compared to the measured data.

reactance to the slot antenna in the region around $150 \mathrm{GHz}$ however the real part of the impedance is closer to $50 \Omega$. Beyond the peak of the real part at $200 \mathrm{GHz}$ the impedance is relatively constant around the $50 \Omega$ value with a reactance around $-\mathrm{j} 60 \Omega$.

The output power of the unpackaged slot antenna integrated UTC-PD mounted on a $6 \mathrm{~mm}$ silicon lens the slot antenna was measured up to $500 \mathrm{GHz}$ using a Thomas Keating (TK) power meter and a Golay Cell (GC). Figure 6 a) shows the experimental arrangement. Two laser tones were combined using a 50:50 optical fibre coupler where one of the laser tones was chopped using a $10 \mathrm{~Hz}$ optical chopping frequency. An Erbium doped fibre amplifier (EDFA) was used after the coupler. For the unpackaged slot antenna, a responsivity of 0.25 $\mathrm{A} / \mathrm{W}$ was measured with $50 \mathrm{~mW}$ optical input power. The responsivity is higher than the UTC-PD reported in [77] but lower than the reported p-i-n PD responsivity. The THz output power was first recorded using the calibrated TK power meter up to $300 \mathrm{GHz}$ and from $150-500 \mathrm{GHz}$ using the GC. The overlap region of $150-200 \mathrm{GHz}$ was used to normalize the GC power readings.

$50.8 \mathrm{~mm}$ diameter TPX lenses were used to collimate the $\mathrm{THz}$ beam and focus it onto the power meter. The recorded power for the resonant slot antenna is shown in Figure 7 alongside the numerically calculated radiated power adjusted for the transit time response and the solid angle of the TPX lens. An ideal current source corresponding to the measured photocurrent of $12.5 \mathrm{~mA}$ was used as the source current in the model. There is a maximum in the output power of $0.5 \mathrm{~mW}$ at $100 \mathrm{GHz}$ which agrees well with the numerical simulations and is higher than the values reported in [77] for comparable optical input powers, i.e. $40 \mathrm{~mW}$ p-i-n photodiode in [77] vs $50 \mathrm{~mW}$ for the UTC-PD. This corresponds to the point in the impedance model where the UTC-PD impedance is closest to the complex conjugate of the antenna impedance as mentioned earlier. A second peak can be observed at $350 \mathrm{GHz}$ in the numerical results and $330 \mathrm{GHz}$ in the measured results. This again corresponds to where the antenna conjugate impedance and UTC-PD impedance are closer. Packaged versions of the slot antenna and the log
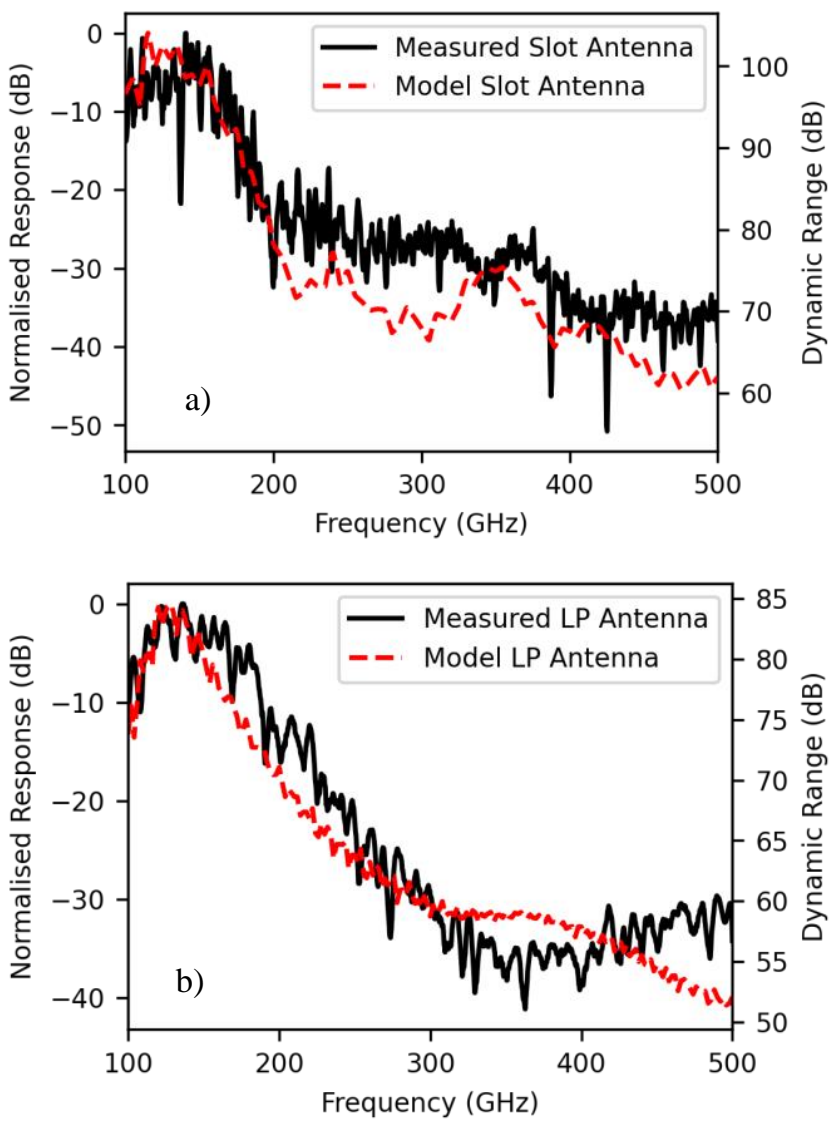

Fig. 8. Measured frequency response and dynamic range for the a) $3 \times 15 \mu \mathrm{m}^{2}$ UTC-PD integrated with a resonant slot antenna and b) a $3 \times 15 \mu \mathrm{m}^{2}$ UTC-PD integrated with a $\log$ periodic antenna compared to the full wave model frequency response.

periodic antenna were measured with a Toptica $1550 \mathrm{~nm}$ InGaAs photoconductor. The responsivity of both devices after packaging was reduced to $0.105 \mathrm{~A} / \mathrm{W}$ and $0.09 \mathrm{~A} / \mathrm{W}$ respectively. The reduction in responsivity is due to fibre misalignment from epoxy shrinkage on curing.

The measured frequency response of the slot and log periodic antennas are shown in Figure 8 a) and b). A peak can be seen around 130 and $150 \mathrm{GHz}$ for each antenna, corresponding to the point where the antennas impedance is closest to the complex conjugate of the UTC-PD impedance. The corresponding full wave model response agrees well with the measured data for both antenna integrated devices.

The peak dynamic range[21] of the packaged devices at 130 $\mathrm{GHz}$ was $105 \mathrm{~dB}$ for the slot antenna device and $85 \mathrm{~dB}$ at 150 $\mathrm{GHz}$ for the $\log$ periodic antenna device. At $500 \mathrm{GHz}$ the dynamic range was $70 \mathrm{~dB}$ for the slot antenna and $56 \mathrm{~dB}$ for the $\log$ periodic antenna at $100 \mathrm{~ms}$ lock-in amplifier integration time. These values are higher or comparable to commercially available $1550 \mathrm{~nm} \mathrm{CW}$ spectroscopy systems[78].

\section{THERMAL MODELLING}

When photodiodes operate at high input optical power, high photocurrent and high bias voltage, the dissipated heat is high. Thermal coupling to the ambient environment is poor as the thermal conductivities of epitaxial layers are relatively low, as shown in Table II. This large amount of heat will cause the temperature to rise inside the absorption and collection layers. 
TABLE II: THERMAL MODELling PARAMETERS

\begin{tabular}{|c|c|c|c|c|c|}
\hline Layer & Material & Thickness $(\mu \mathrm{m})$ & $\begin{array}{c}\text { Thermal } \\
\text { Conductivity } \\
\left(\mathrm{W} / \mathrm{m}^{2} \cdot \mathrm{K}\right) \\
\end{array}$ & $\begin{array}{c}\text { Heat } \\
\text { Capacity } \\
(\mathrm{J} / \mathrm{kg} \cdot \mathrm{K}) \\
\end{array}$ & $\begin{array}{c}\text { Temperature Change } \\
\left({ }^{\circ} \mathrm{C}\right)\end{array}$ \\
\hline Passivation & $\mathrm{SiO}_{2} / \mathrm{Si}_{3} \mathrm{~N}_{4}$ & 2 & $1.4 / 30$ & $680 / 673$ & \\
\hline $\mathrm{P}$ electrode & $\mathrm{Ti} / \mathrm{Pt} / \mathrm{Au}$ & $0.075 / 0.05 / 0.4$ & $17 / 72 / 314$ & & 1.9 \\
\hline $\mathrm{P}$ contact & InGaAsP Q1.3 & 0.2 & 7.2 & 337 & 11 \\
\hline Absorber & InGaAs & 0.12 & 5 & 300 & 6.2 \\
\hline Collector & InP & 0.3 & 68 & 310 & 3.5 \\
\hline Waveguide & InGaAsP Q1.3 & 0.3 & 7.2 & 337 & 31.4 \\
\hline $\mathrm{N}$ contact & InP & 0.6 & 68 & 310 & 6.1 \\
\hline Substrate & S.I. InP & 290 & 68 & 310 & 53.7 \\
\hline $\begin{array}{l}\text { Bonding } \\
\text { Layer }\end{array}$ & Nitrocellulose & 15 & 0.142 & 1300 & 50.5 \\
\hline Lens & $\mathrm{Si}$ & 3700 & 142 & 700 & 0.87 \\
\hline
\end{tabular}

In the temperature change column of Table II, the values are calculated by using the temperature at the top of the layer subtracting the temperature at the bottom of the layer.

With increasing temperature, lattice thermal vibration increases and causes increased carrier scattering. Increased lattice scattering lowers electron mobility[79] and increases the transit time of electrons passing through the collection layer, eventually contributing to the RF output power saturating. To optimise thermal performance of UTC-PDs, knowledge of the temperature distribution of the device structure and identification of the heat flow bottlenecks, are needed. The heat transfer module in COMSOL Multiphysics was used to simulate the thermal distribution inside the UTC-PD. The device structure used for thermal modelling is shown in Figure 9. The $3 \times 15 \mu \mathrm{m}^{2}$ antenna integrated waveguide UTC-PD is attached to a hyper-hemispherical Si lens (diameter $=6 \mathrm{~mm}$ ).

For energy to be conserved, the total power delivered to the photodiode must be equal to the sum of the output power delivered by the photodiode, contact heating, and power dissipated in the photodiode[80], [81], as in equation (1). $\mathrm{P}_{\mathrm{opt}}$ is the absorbed optical input power, $\mathrm{P}_{\mathrm{DC}}$ is the $\mathrm{DC}$ electrical power supplied to the photodiode, $\mathrm{P}_{\mathrm{RF}}$ is the radiated $\mathrm{RF}$ power from antenna integrated UTC-PD, $\mathrm{P}_{\text {cont }}$ is the joule heat on contacts, and $\mathrm{P}_{\mathrm{dis}}$ is the remaining power to heat the device.

$$
P_{o p t}+P_{D C}=P_{R F}+P_{c o n t}+P_{\text {dis }}
$$

Based on the experimental results for a $3 \times 15 \mu \mathrm{m}^{2}$ antenna integrated UTC-PD, the UTC-PD generates $13.5 \mathrm{~mA} \mathrm{DC}$ photocurrent and $60 \mu \mathrm{W}$ RF power with $64 \mathrm{~mW}$ input optical power and $-2 \mathrm{~V}$ bias voltage. The optical power coupling ratio

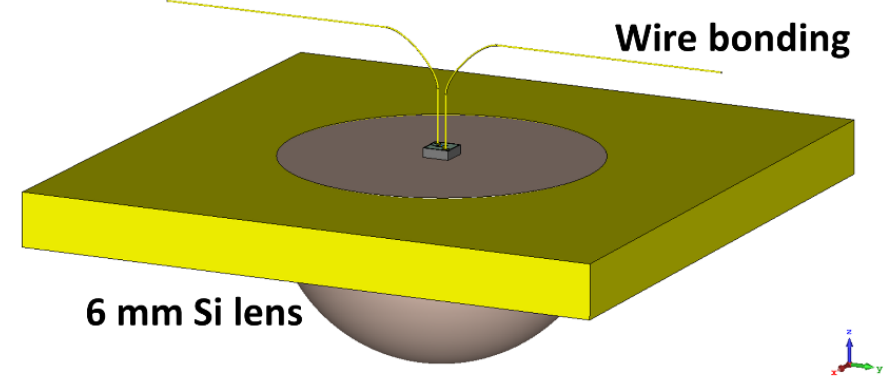

Fig. 9. Schematic diagram of an antenna integrated UTC-PD on a $6 \mathrm{~mm}$ Silicon lens used for thermal modelling. is about $45 \%$ between the waveguide of UTC-PD and the lensed fibre (spot size $=2.4 \mathrm{um}$ )[36]. The series resistance of the UTCPD was measured as $17 \Omega$. Based on equation (1), the calculated dissipated power inside a $3 \times 15 \mu \mathrm{m}^{2}$ antenna integrated UTC$\mathrm{PD}$ is $52.5 \mathrm{~mW}$, which was set as the heat source in the thermal modelling. Besides heat conduction, convection is another type of heat transfer for UTC-PDs. The surface of heated antenna UTC-PDs is at higher than ambient room temperature $\left(20{ }^{\circ} \mathrm{C}\right)$ shown in Figure $10 \mathrm{a}$ ), therefore the convective heat flux between air and the device should be included though the heat convection effect is very limited because the surface area of UTC-PDs is very small. Typical convective heat transfer coefficients for free air convection are in the range of $0.5-1000$

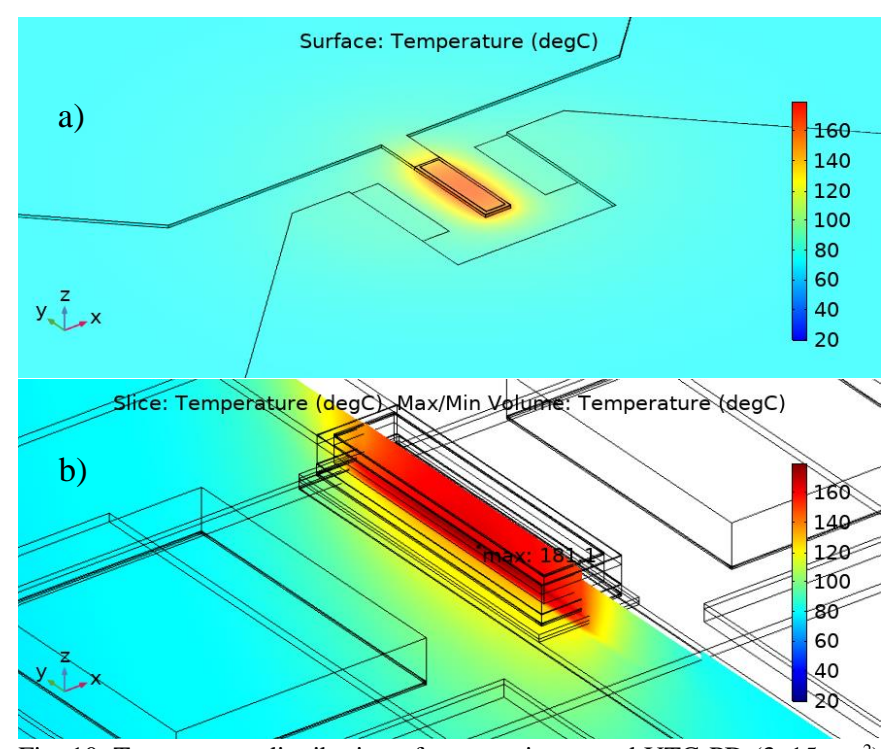

Fig. 10. Temperature distribution of antenna integrated UTC-PD $\left(3 \times 15 \mu \mathrm{m}^{2}\right)$ on Si lens, (a) Temperature distribution on the top surface, (b) Temperature distribution of $\mathrm{P}$ ridge cross section.

$\mathrm{W} /\left(\mathrm{m}^{2} \cdot \mathrm{K}\right)$, and for forced air convection the value is in the range of $10-1000 \mathrm{~W} /\left(\mathrm{m}^{2} \cdot \mathrm{K}\right)$. In this thermal modelling, the air convective coefficient is set to $5 \mathrm{~W} /\left(\mathrm{m}^{2} \cdot \mathrm{K}\right)$ from [82].

Different values of air convective coefficient were applied in the modelling to see the influence on the temperature distribution $\left(1,10\right.$, and $\left.20 \mathrm{~W} /\left(\mathrm{m}^{2} \cdot \mathrm{K}\right)\right)$. The impact on the maximum temperature inside antenna integrated UTC-PDs is limited, less than $1{ }^{\circ} \mathrm{C}$. The simulated temperature distribution inside a $3 \times 15 \mu \mathrm{m}^{2}$ antenna integrated UTC-PD is shown in 


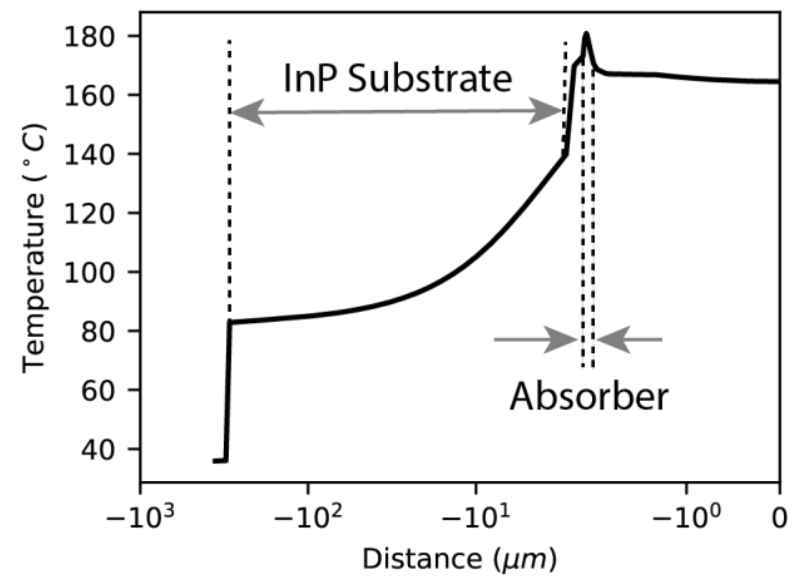

Fig. 11. Temperature distribution of antenna integrated UTC-PD $\left(3 \times 15 \mu \mathrm{m}^{2}\right)$ on Si lens through the central $\mathrm{z}$ coordinate of the structure descending from the top of the device to the adhesion layer in log scale.

Figure $10 \mathrm{~b}$ ), indicating that a maximum temperature of $181^{\circ} \mathrm{C}$ $(454 \mathrm{~K})$ is reached in the absorption layer. From Table II, there is $50.5{ }^{\circ} \mathrm{C}$ temperature difference across the bonding layer, between the Semi Insulating (S.I.) InP substrate and the Si lens. On the top surface of UTC-PD, most of the heat is concentrated in the P-contact area, and the antenna metal does not contribute significantly to heat dissipation. The cross-section temperature distribution suggests that heat gathers inside the P-ridge and only a small part of the heat dissipates through the InP substrate.

Figure 11 shows the change of temperature along the $\mathrm{z}$-axis in the centre of the P-ridge, from the top of the device to the $\mathrm{Si}$ lens. The thermal conductivity of the adhesive used to attach the UTC-PD and Si lens is very low, only $0.142 \mathrm{~W} /(\mathrm{m} \cdot \mathrm{K})$. The calculated thermal resistance for this adhesive layer is 499.2 $\mathrm{K} / \mathrm{W}$. Adhesives with higher thermal conductivity could be used in the future, to decrease the thermal resistance of this layer. The temperature change through the S.I. InP substrate is $53.7{ }^{\circ} \mathrm{C} .70 \%$ of the temperature change happens within $10 \mu \mathrm{m}$ depth beneath the $\mathrm{N}$-contact layer, which has a high thermal resistance of $3268 \mathrm{~K} / \mathrm{W}$. This results in poor heat dissipation through the InP substrate. Figure 11 shows most of the heat is blocked in the P-ridge and the temperature is as high as 166.85 ${ }^{\circ} \mathrm{C}(440 \mathrm{~K})$ at the top of P-contact. Although the antenna metal is connected to P-contact, there is very limited heat transferred from the P-ridge to the bow-tie antenna because of the high thermal resistance $(14642 \mathrm{~K} / \mathrm{W})$. Such high thermal resistance is caused by small cross-section area (only $3 \mathrm{um} \times 435 \mathrm{~nm}$ ) through which the heat is conducted from P-contact to antenna metal, even though Gold has high thermal conductivity, 314

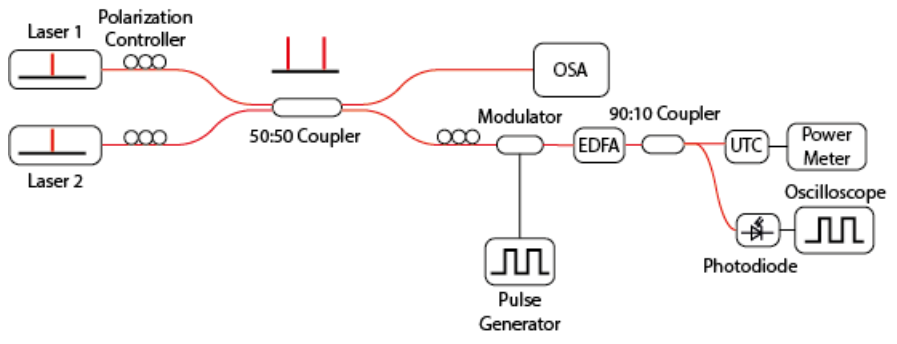

Fig. 12. Schematic diagram for pulsed power signal generation and measurement.
$\mathrm{W} /(\mathrm{m} \cdot \mathrm{K})$. The high thermal resistance blocks the heat path and confines the heat inside the absorption layer. Lowering these thermal resistances, through appropriate heat sinking design, would improve the heat dissipation and reduce the maximum temperature inside antenna integrated UTC-PDs. Replacing the nitrocellulose bonding layer between the silicon lens and substrate with a higher thermal conductivity adhesive, as well as thinning the substrate, could also provide some improvement to heat dissipation.

\section{Pulse Power Measurements}

Under high power operation there are two main mechanisms that limit the output RF power from a photodiode. The first is the space charge effect caused by an accumulation of carriers in the depletion layer of photodiodes causing a distortion to the field profile[83]. Due to the high electron velocity in the depletion layer the space charge effect is reduced in UTC-PDs increasing the saturation current by an order of magnitude[43]. The second limiting factor is thermal failure of the device at high optical input powers. The space charge effect in the photodiode can be reduced by applying a higher bias, this comes at the expense of increased joule heating of the device which can lead to thermal failure.

The effects of self-heating can be mitigated by pulsing the optical drive signal to the photodiode. Incorporating a MachZehnder intensity modulator and pulse generator into a standard optical heterodyne experiment, as shown in Figure 12, allows for varying pulse duty cycles. The temporal width of the pulse should be shorter than the heating time of the photodiode. From the thermal modelling presented in Section IV the internal heating time of the photodiode is shown in Figure 13. For an example pulse width of 20 nanoseconds the self-heating of the

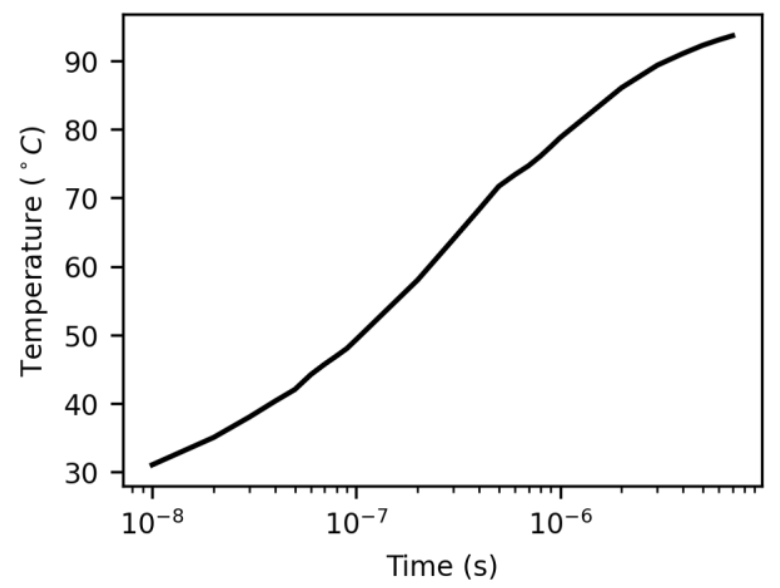

Fig. 13. Internal heating time for a $3 \times 15 \mu \mathrm{m}^{2} \mathrm{UTC}-\mathrm{PD}$ based on an $81.1 \mathrm{~mW}$ heat source in the absorber layer.

device would be minimal, around $4{ }^{\circ} \mathrm{C}$. The pulse generator used was an AIM TTI TGP 300 series. A 20 ns pulse was used to drive the Mach-Zehnder modulator, which was biased at the null point. The input optical power was varied using an erbium doped fibre amplifier (EDFA) with maximum output optical power of $18 \mathrm{dBm}$ measured before the lensed fibre. The heterodyne beat frequency was set using two laser diodes, one fixed laser Rio Orion series at $1553 \mathrm{~nm}$ and a tuneable laser diode set to a $100 \mathrm{GHz}$ difference frequency. 

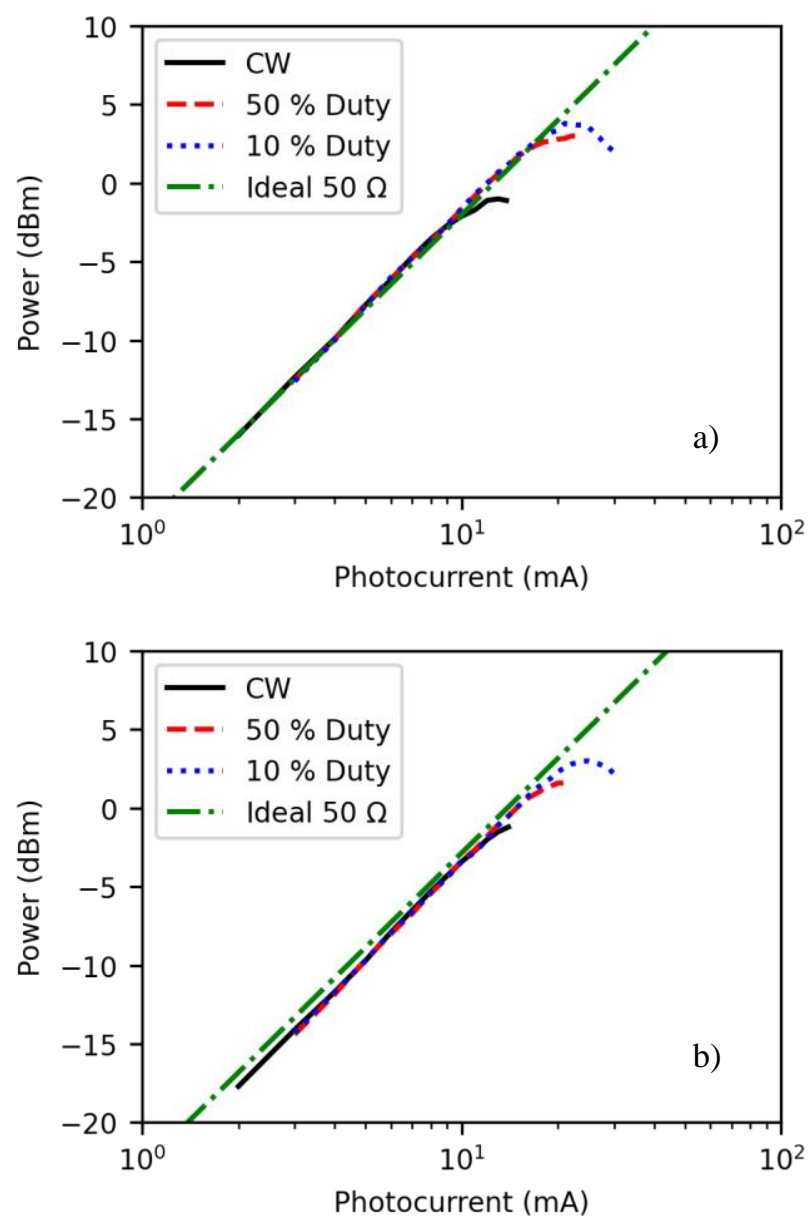

Fig. 14. Saturated power measurements for the $3 \times 10 \mu \mathrm{m}^{2} \mathrm{a}$ ) and b) $3 \times 15 \mu \mathrm{m}^{2}$ UTC-PD with the expected output power delivered to an ideal $50 \Omega$ load from the full wave UTC-PD model.

Two polarization controllers were used to set the laser polarizations parallel to each other. Another controller was placed before the modulator to align the polarization of the two laser tones to the slow axis of the modulator in order to maximize the extinction ratio. The extinction ratio after amplification in the EDFA was around $19 \mathrm{~dB}$. At the modulator null point, the measured RF power at $100 \mathrm{GHz}$ was $-41 \mathrm{dBm}$. The "off" state power should be subtracted from the RF power readings when calculating the peak power of output RF pulses. To account for this, the pulses were measured using an oscilloscope and a low frequency photodiode via a 90:10 fibre tap. The device was mounted on a metal block maintained at a constant temperature of $20{ }^{\circ} \mathrm{C}$ using a peltier cooler. The $\mathrm{RF}$ power was extracted from the device with an air coplanar probe and measured using an Agilent power meter. A flexible W band waveguide was used in between the probe and power meter head to reduce mechanical strain. The loss of the waveguide was measured using a network analyzer and was found to be 3.2 $\mathrm{dB}$ at $100 \mathrm{GHz}$. The photocurrent was recorded using an Agilent Multi meter connected to the device via a bias tee integrated with the co-planar probe.

The photodiode was biased at $-3 \mathrm{~V}$ as the optical power was increased. The recorded power is shown in Figure 14 with both $\mathrm{CW}$ and pulsed operation modes. $\mathrm{CW}$ operation saturates around $10 \mathrm{~mA}$ of measured photocurrent. Applying a $20 \mathrm{~ns}$ pulse to the photodiode with a $50 \%$ duty cycle increased the saturation point to a peak photocurrent of around $17 \mathrm{~mA}$. Reducing the duty cycle to $10 \%$ the peak photocurrent was around $20 \mathrm{~mA}$. The peak output powers are corrected for the losses in both the probe and the waveguide. The ideal output power delivered to a $50 \Omega$ load is also calculated using the full wave model of the UTC-PD integrated with a CPW. There is good agreement between the measured output powers at 100 $\mathrm{GHz}$ and the full wave model results up to the onset of saturation. For the $3 \times 10 \mu \mathrm{m}^{2}$ the peak output power at $10 \%$ duty cycle was $3.8 \mathrm{dBm}$ while for the $3 \times 15 \mu \mathrm{m}^{2}$ device the peak power was $3.0 \mathrm{dBm}$. The difference in the two output powers is a result of the steeper $3 \mathrm{~dB}$ roll off for the $3 \times 15 \mu \mathrm{m}^{2}$ device which was measured to be $60 \mathrm{GHz}$ in Section II compared to 70 $\mathrm{GHz}$ for the $3 \times 10 \mu \mathrm{m}^{2}$ device. A clear difference between the $\mathrm{CW}$ power measurements and pulsed power measurements can be seen, indicating that thermal effects are a strong limiting factor in the output power of small active area UTC-PDs.

\section{CONCLUSIONS}

We have demonstrated an equivalent circuit design tool for the modelling and evaluation of UTC-PD impedance, which has been used to design antenna integrated UTC-PDs. The output response of the antenna integrated UTC-PDs was measured and compared with the full wave model. Good agreement between the measured data and model was demonstrated up to $500 \mathrm{GHz}$ where the lumped element model is expected to lose validity. Using the model, we have shown that, to maximize the coupling of output power from the UTC-PD to a load, complex conjugate impedance matching is needed. We have carried out a thermal analysis of the UTC-PD and identified that limitations arising from thermal effects are a key factor in determining the saturated output power. To improve output power from photodiodes to compete with electronics-based sources, optimization of heat dissipation within the device is required through appropriate heat sinking. We have measured the peak output power of two sizes of devices with peak output powers of $3.8 \mathrm{dBm}$ at $100 \mathrm{GHz}$ recorded for a $3 \times 10 \mu \mathrm{m}^{2} \mathrm{UTC}-\mathrm{PD}$ using a pulsed optical input. A $4.8 \mathrm{~dB}$ increase in the maximum output power was measured between $\mathrm{CW}$ operation and pulsed operation at a $10 \%$ duty cycle for the $3 \times 10 \mu \mathrm{m}^{2}$ photodiode, confirming the results of the thermal modelling that poor thermal dissipation is a major issue in small active area photodiodes.

\section{REFERENCES}

[1] S. S. Dhillon et al., "The 2017 terahertz science and technology roadmap," Journal of Physics D: Applied Physics, vol. 50, no. 4. Institute of Physics Publishing, p. 43001, Feb. 02, 2017, doi: 10.1088/1361-6463/50/4/043001.

[2] A. J. Seeds et al., "Coherent terahertz photonics," Opt. Express, vol. 21, no. 19, p. 22988, Sep. 2013, doi: 10.1364/oe.21.022988.

[3] A. Maestrini et al., "Schottky diode-based terahertz frequency multipliers and mixers," Comptes Rendus Phys., vol. 11, no. 7, pp. 480-495, 2010, doi: https://doi.org/10.1016/j.crhy.2010.05.002.

[4] C. H. Li, C. L. Ko, C. N. Kuo, M. C. Kuo, and D. C. Chang, "A 340 $\mathrm{GHz}$ triple-push oscillator with differential output in $40 \mathrm{~nm}$ CMOS," IEEE Microw. Wirel. Components Lett., vol. 24, no. 12, pp. 863-865, Dec. 2014, doi: 10.1109/LMWC.2014.2352936.

[5] C. H. Li, T. Y. Chiu, and W. M. Wu, "CMOS devices and circuits for THz applications," in Asia-Pacific Microwave Conference 
Proceedings, APMC, Jan. 2019, vol. 2018-Novem, pp. 1151-1153, doi: 10.23919/APMC.2018.8617199.

[6]

C. H. Li, T. C. Yan, Y. Chang, C. Chen, and C. N. Kuo, "Low-cost high-performance CMOS terahertz imaging system," in ISOCC 2015 - International SoC Design Conference: SoC for Internet of Everything (IoE), Feb. 2016, pp. 49-50, doi: 10.1109/ISOCC.2015.7401634.

[7] H. Eisele, "Third-harmonic power extraction from InP gunn devices up to $455 \mathrm{GHz}$," IEEE Microw. Wirel. Components Lett., vol. 19, no. 6, pp. 416-418, Jun. 2009, doi: 10.1109/LMWC.2009.2020044 M. S. Vitiello and A. Tredicucci, "Tunable Emission in THz Quantum Cascade Lasers," IEEE Trans. Terahertz Sci. Technol., vol. 1, no. 1, pp. 76-84, 2011, doi: 10.1109/TTHZ.2011.2159543.

[9] WadeA. et al., "Magnetic-field-assisted terahertz quantum cascade laser operating up to $225 \mathrm{~K}$," Nat. Photonics, vol. 3, no. 1, pp. 4145, Jan. 2009, doi: 10.1038/nphoton.2008.251.

[10] R. B. Kohlhaas et al., "Improving the dynamic range of InGaAsbased $\mathrm{THz}$ detectors by localized beryllium doping: up to $70 \mathrm{~dB}$ at 3 THz," Opt. Lett., vol. 43, no. 21, p. 5423, Nov. 2018, doi: 10.1364/ol.43.005423.

[11] U. Nandi et al., "ErAs:In(Al)GaAs photoconductor-based time domain system with $45 \mathrm{THz}$ single shot bandwidth and emitted terahertz power of $164 \mu \mathrm{W}$," Opt. Lett., vol. 45, no. 10, p. 2812, May 2020, doi: 10.1364/ol.388870.

[12] A. D. J. F. Olvera, H. Lu, A. C. Gossard, and S. Preu, "Continuouswave $1550 \mathrm{~nm}$ operated terahertz system using ErAs:In(Al)GaAs photo-conductors with $52 \mathrm{~dB}$ dynamic range at $1 \mathrm{THz}$," Opt. Express, vol. 25, no. 23, p. 29492, Nov. 2017, doi: 10.1364/oe.25.029492.

[13] P. G. Huggard et al., "Efficient generation of guided millimeterwave power by photomixing," IEEE Photonics Technol. Lett., vol. 14, no. 2, pp. 197-199, Feb. 2002, doi: 10.1109/68.980513.

[14] T. I. and S. K. and N. S. and T. Furuta, "High-Speed Response of Uni-Traveling-Carrier Photodiodes," Jpn. J. Appl. Phys., vol. 36, no. 10 R, p. 6263,1997 , [Online]. Available: http://stacks.iop.org/1347-4065/36/i=10R/a=6263.

[15] T. Ishibashi, N. Shimizu, S. Kodama, H. Ito, T. Nagatsuma, and T. E. D.-N. Furuta M. and Bowers, J., "Uni-Traveling-Carrier Photodiodes," in Ultrafast Electronics and Optoelectronics, 1997, vol. 13, p. UC3, [Online]. Available:

http://www.osapublishing.org/abstract.cfm?URI=UEO-1997-UC3.

[16] M. Theuer, S. S. Harsha, D. Molter, G. Torosyan, and R. Beigang, "Terahertz time-domain spectroscopy of gases, liquids, and solids," ChemPhysChem, vol. 12, no. 15. Wiley-VCH Verlag, pp. 26952705, Oct. 24, 2011, doi: 10.1002/cphc.201100158.

[17] J.-Y. Kim, H.-J. Song, M. Yaita, A. Hirata, and K. Ajito, “CW-THz vector spectroscopy and imaging system based on $155-\mu \mathrm{m}$ fiberoptics," Opt. Express, vol. 22, no. 2, p. 1735, Jan. 2014, doi: $10.1364 /$ oe.22.001735.

[18] S. Hisatake, G. Kitahara, K. Ajito, Y. Fukada, N. Yoshimoto, and T. Nagatsuma, "Phase-Sensitive Terahertz Self-Heterodyne System Based on Photodiode and Low-Temperature-Grown GaAs Photoconductor at $1.55 \$ \backslash \mathrm{mu}\{\backslash \mathrm{rm} \mathrm{m}\}$ \$, IEEE Sens. J., vol. 13, no. 1, pp. 31-36, Sep. 2012, doi: 10.1109/jsen.2012.2218281.

[19] S. R. Chick, B. N. Murdin, G. Matmon, and M. Naftaly, "Metrology of complex refractive index for solids in the terahertz regime using frequency domain spectroscopy," Metrologia, vol. 55, no. 6, p. 771, Oct. 2018, doi: 10.1088/1681-7575/aae2c9.

[20] T. Nagatsuma, G. Ducournau, and C. C. Renaud, "Advances in terahertz communications accelerated by photonics," Nat. Photonics, vol. 10, p. 371, May 2016, [Online]. Available: https://doi.org/10.1038/nphoton.2016.65.

[21] M. Naftaly and R. Dudley, "Methodologies for determining the dynamic ranges and signal-to-noise ratios of terahertz time-domain spectrometers," Opt. Lett., vol. 34, no. 8, p. 1213, Apr. 2009, doi: 10.1364/ol.34.001213

[22] J. Neu and C. A. Schmuttenmaer, "Tutorial: An introduction to terahertz time domain spectroscopy (THz-TDS)," J. Appl. Phys., vol. 124 , no. 23 , p. 231101 , Dec. 2018 , doi: 10.1063/1.5047659. W. Withayachumnankul and M. Naftaly, "Fundamentals of measurement in terahertz time-domain spectroscopy," Journal of Infrared, Millimeter, and Terahertz Waves, vol. 35, no. 8. Springer New York LLC, pp. 610-637, Dec. 12, 2014, doi: 10.1007/s10762013-0042-z.
R. Wilk, T. Hochrein, M. Koch, M. Mei, and R. Holzwarth,
"Terahertz spectrometer operation by laser repetition frequency tuning," J. Opt. Soc. Am. B, vol. 28, no. 4, p. 592, Apr. 2011, doi: 10.1364/JOSAB.28.000592.

[25] N. Vieweg et al., "Terahertz-time domain spectrometer with $90 \mathrm{~dB}$ peak dynamic range," J. Infrared, Millimeter, Terahertz Waves, vol. 35, no. 10, pp. 823-832, Jul. 2014, doi: 10.1007/s10762-014-00859.

[26] S. Verghese, K. A. McIntosh, and E. R. Brown, "Optical and terahertz power limits in the low-temperature-grown GaAs photomixers," Appl. Phys. Lett., vol. 71, no. 19, pp. 2743-2745, Nov. 1997, doi: 10.1063/1.120445.

[27] S. Preu, G. H. Döhler, S. Malzer, L. J. Wang, and A. C. Gossard, "Tunable, continuous-wave Terahertz photomixer sources and applications," J. Appl. Phys., vol. 109, no. 6, p. 061301, Mar. 2011, doi: 10.1063/1.3552291.

[28] E. R. Brown, F. W. Smith, and K. A. McIntosh, "Coherent millimeter-wave generation by heterodyne conversion in lowtemperature-grown GaAs photoconductors," J. Appl. Phys., vol. 73, no. 3, pp. 1480-1484, Feb. 1993, doi: 10.1063/1.353222.

[29] E. Peytavit, P. Latzel, F. Pavanello, G. Ducournau, and J. F. Lampin, "Milliwatt output power generated in the J-Band by a GaAs photomixer," 2013, doi: 10.1109/IRMMWTHz.2013.6665739.

[30] C. Baker, I. S. Gregory, M. J. Evans, W. R. Tribe, E. H. Linfield, and M. Missous, "All-optoelectronic terahertz system using lowtemperature-grown InGaAs photomixers," Opt. Express, vol. 13, no 23, pp. 9639-9644, Nov. 2005, doi: 10.1364/OPEX.13.009639. C. Baker, I. S. Gregory, W. R. Tribe, M. J. Evans, M. Missous, and E. H. Linfield, "Continuous-wave terahertz photomixing in lowtemperature InGaAs," in Conference Digest of the 2004 Joint 29th International Conference on Infrared and Millimeter Waves and 12th International Conference on Terahertz Electronics, 2004, pp. 367-368, doi: 10.1109/icimw.2004.1422114.

[32] B. Sartorius, D. Stanze, T. Göbel, D. Schmidt, and M. Schell, "Continuous wave terahertz systems based on $1.5 \mu \mathrm{m}$ telecom technologies," J. Infrared, Millimeter, Terahertz Waves, vol. 33, no. 4, pp. 405-417, Apr. 2012, doi: 10.1007/s10762-011-9849-7.

[33] D. Stanze, A. Deninger, A. Roggenbuck, S. Schindler, M. Schlak, and B. Sartorius, "Compact cw terahertz spectrometer pumped at $1.5 \mu \mathrm{m}$ wavelength," J. Infrared, Millimeter, Terahertz Waves, vol. 32, no. 2, pp. 225-232, Dec. 2011, doi: 10.1007/s10762-010-97518.

[34] H. Ito, S. Kodama, Y. Muramoto, T. Furuta, T. Nagatsuma, and T Ishibashi, "High-speed and high-output InP-InGaAs unitravelingcarrier photodiodes," Sel. Top. Quantum Electron. IEEE J., vol. 10, no. 4, pp. 709-727, Jul. 2004, doi: 10.1109/JSTQE.2004.833883.

[35] P. Latzel et al., "Generation of $\mathrm{mW}$ Level in the 300-GHz Band Using Resonant-Cavity-Enhanced Unitraveling Carrier Photodiodes," IEEE Trans. Terahertz Sci. Technol., vol. 7, no. 6, pp. 800-807, Nov. 2017, doi: 10.1109/TTHZ.2017.2756059.

[36] C. C. Renaud, D. Moodie, M. Robertson, and A. J. Seeds, "High output power at $110 \mathrm{GHz}$ with a waveguide Uni-travelling carrier photodiode," in Conference Proceedings - Lasers and ElectroOptics Society Annual Meeting-LEOS, 2007, pp. 782-783, doi: 10.1109/LEOS.2007.4382641.

[37] S. Nellen, R. Kohlhaas, L. Liebermeister, S. Breuer, B. Globisch, and M. Schell, "Continuous Wave Terahertz Generation from Photodiode-Based Emitters with up to $200 \mu \mathrm{W}$ Terahertz Power," in International Conference on Infrared, Millimeter, and Terahertz Waves, IRMMW-THz, Oct. 2018, vol. 2018-Septe, doi: 10.1109/IRMMW-THz.2018.8509858.

[38] D. Wake et al., "Monolithic integration of $1.5 \mu \mathrm{m}$ optical preamplifier and PIN photodiode with a gain of $20 \mathrm{~dB}$ and a bandwidth of 35GHz," in Conference on Lasers and Electro-Optics, 1990, vol. 7, p. CPD18.

[39] K. Kato, S. Hata, A. Kozen, and J. Yoshida, "High-efficiency waveguide InGaAs P-I-N photodiode with bandwidth of greater than 40 GHz," in Optical Fiber Communication, 1991, vol. 4, p. ThO4, doi: 10.1364/OFC.1991.ThO4.

[40] K. S. Giboney, M. J. W. Rodwell, and J. E. Bowers, "Travelingwave photodetectors," Photonics Technol. Lett. IEEE, vol. 4, no. 12, pp. 1363-1365, 1992.

[41] K. S. Giboney, M. J. W. Rodwell, and J. E. Bowers, "Travelingwave photodetector theory," Microw. Theory Tech. IEEE Trans., vol. 45, no. 8 PART 2, pp. 1310-1319, 1997, doi: 
E. Rouvalis, C. C. Renaud, D. G. Moodie, M. J. Robertson, and A. J. Seeds, "Continuous Wave Terahertz Generation From Ultra-Fast InP-Based Photodiodes," IEEE Trans. Microw. Theory Tech., vol. 60, no. 3, pp. 509-517, Mar. 2012, doi:

10.1109/TMTT.2011.2178858.

[43] T. Nagatsuma, H. Ito, and T. Ishibashi, "High-power RF photodiodes and their applications," Laser Photonics Rev., vol. 3, no. 1-2, pp. 123-137, Feb. 2009, doi: 10.1002/lpor.200810024.

[44] N. Li et al., "High-Saturation-Current Charge-Compensated InGaAs-InP Uni-Traveling-Carrier Photodiode," IEEE Photonics Technol. Lett., vol. 16, no. 3, pp. 864-866, Mar. 2004, doi: 10.1109/LPT.2004.823773.

[45] M. Chtioui et al., "High-performance uni-traveling-carrier photodiodes with a new collector design," IEEE Photonics Technol. Lett., vol. 20, no. 13, pp. 1163-1165, Jul. 2008, doi: 10.1109/LPT.2008.924651.

[46] D. H. Jun, J. H. Jang, I. Adesida, and J. I. Song, "Improved efficiency-bandwidth product of modified uni-traveling carrier photodiode structures using an undoped photo-absorption layer," Japanese J. Appl. Physics, Part 1 Regul. Pap. Short Notes Rev. Pap., vol. 45, no. 4 B, pp. 3475-3478, Apr. 2006, doi: 10.1143/JJAP.45.3475.

[47] X. Wang, N. Duan, H. Chen, and J. C. Campbell, "InGaAs-InP Photodiodes with High Responsivity and High Saturation Power," IEEE Photonics Technol. Lett., vol. 19, no. 16, pp. 1272-1274, Aug. 2007, doi: 10.1109/LPT.2007.902274.

[48] G. Zhou et al., "High-power waveguide integrated modified unitraveling-carrier (UTC) photodiode with $5 \mathrm{dBm} \mathrm{RF}$ output power at 120 GHz," 2016 Opt. Fiber Commun. Conf. Exhib., pp. 1-3, 2016.

[49] Q. Li et al., "High-Power Evanescently Coupled Waveguide MUTC Photodiode with >105-GHz Bandwidth," J. Light. Technol., vol. 35, no. 21, pp. 4752-4757, Nov. 2017, doi: 10.1109/JLT.2017.2759210. M. Ali, L. E. Garcia-Munoz, S. Nellen, B. Globisch, and G. Carpintero, "High-speed Terahertz PIN Photodiode with WR-3 Rectangular Waveguide Output," in 2020 45th International Conference on Infrared, Millimeter, and Terahertz Waves (IRMMW-THz), Nov. 2020, pp. 1-2, doi: 10.1109/IRMMWTHz46771.2020.9370781.

[51] A. Wakatsuki, T. Furuta, Y. Muramoto, T. Yoshimatsu, and H. Ito, "High-power and broadband sub-terahertz wave generation using a J-band photomixer module with rectangular-waveguide output port," 2008, doi: 10.1109/ICIMW.2008.4665566.

[52] H. Ito, T. Furuta, Y. Muramoto, T. Ito, and T. Ishibashi, "Photonic millimetre- and sub-millimetre-wave generation using J-band rectangular-waveguide-output uni-travelling-carrier photodiode module," Electron. Lett., vol. 42, no. 24, pp. 1424-1425, 2006, doi: 10.1049/el:20063033.

[53] T. Kurokawa, T. Ishibashi, M. Shimizu, K. Kato, and T. Nagatsuma, "Over $300 \mathrm{GHz}$ bandwidth UTC-PD module with $600 \mathrm{GHz}$ band rectangular-waveguide output," Electron. Lett., vol. 54, no. 11, pp. 705-706, May 2018, doi: 10.1049/el.2018.0932.

[54] T. Nagatsuma et al., "Characterisation of uni-travelling-carrier photodiode monolithically integrated with matching circuit," Electron. Lett., vol. 37, no. 20, pp. 1246-1247, Sep. 2001, doi: 10.1049/el:20010858.

[55] H. Ito and T. Nagatsuma, "High-speed and high-output-power unitraveling-carrier photodiodes," in Active and Passive Optical Components for WDM Communications III, Aug. 2003, vol. 5246, p. 465 , doi: $10.1117 / 12.511223$

[56] H. Ito, T. Yoshimatsu, H. Yamamoto, and T. Ishibashi, "Broadband photonic terahertz-wave emitter integrating UTC-PD and novel planar antenna," in Terahertz Physics, Devices, and Systems VII: Advanced Applications in Industry and Defense, May 2013, vol. 8716, p. 871602, doi: $10.1117 / 12.2015523$.

[57] E. Rouvalis, C. C. Renaud, D. G. Moodie, M. J. Robertson, and A. J. Seeds, "Traveling-wave Uni-Traveling Carrier Photodiodes for continuous wave THz generation," Opt. Express, vol. 18, no. 11, p. 11105, May 2010, doi: 10.1364/oe.18.011105.

[58] H. Ito, T. Yoshimatsu, H. Yamamoto, and T. Ishibashi, "Broadband photonic terahertz-wave emitter integrating uni-traveling-carrier photodiode and self-complementary planar antenna," Opt. Eng., vol. 53, no. 3, p. 031209, Mar. 2014, doi: 10.1117/1.oe.53.3.031209.

[59] H. Ito and T. Ishibashi, "Photonic terahertz-wave generation using slot-antenna-integrated uni-traveling-carrier photodiodes," IEEE J.
Sel. Top. Quantum Electron., vol. 23, no. 4, Jul. 2017, doi: 10.1109/JSTQE.2017.2657678.

[60] F. Nakajima, T. Furuta, and H. Ito, "High-power continuousterahertz-wave generation using resonant-antenna-integrated unitravelling-carrier photodiode," Electron. Lett., vol. 40, no. 20, pp. 1297-1299, Sep. 2004, doi: 10.1049/el:20046431.

[61] Y. Fu, H. Pan, and J. C. Campbell, "Photodiodes With Monolithically Integrated Wilkinson Power Combiner," IEEE J. Quantum Electron., vol. 46, no. 4, pp. 541-545, 2010, doi: 10.1109/JQE.2009.2035058.

[62] Y. Fu, H. Pan, Z. Li, and J. Campbell, "High linearity photodiode array with monolithically integrated wilkinson power combiner," in Proceedings - 2010 IEEE International Topical Meeting on Microwave Photonics, MWP 2010, 2010, pp. 111-113, doi: 10.1109/MWP. 2010.5664212.

[63] K. Sakuma, J. Haruki, G. Sakano, K. Kato, S. Hisatake, and T. Nagatsuma, "Coherent THz wave combiner composed of arrayed uni-traveling carrier photodiodes and planar lightwave circuit," in Terahertz, RF, Millimeter, and Submillimeter-Wave Technology and Applications IX, Feb. 2016, vol. 9747, p. 97471O, doi: 10.1117/12.2212017.

[64] P. Runge et al., "High-Power Waveguide Integrated Modified UniTravelling Carrier Photodiode Arrays," Nov. 2018, doi: 10.1109/MWP.2018.8552854.

[65] M. Che, Y. Matsuo, H. Kanaya, H. Ito, T. Ishibashi, and K. Kato, "Optoelectronic THz-Wave Beam Steering by Arrayed Photomixers with Integrated Antennas," IEEE Photonics Technol. Lett., vol. 32, no. 16, pp. 979-982, Aug. 2020, doi: 10.1109/LPT.2020.3007415.

[66] T. Ishibashi, Y. Muramoto, T. Yoshimatsu, and H. Ito, "Unitraveling-Carrier Photodiodes for Terahertz Applications," IEEE J. Sel. Top. Quantum Electron., vol. 20, no. 6, pp. 79-88, Nov. 2014, doi: 10.1109/JSTQE.2014.2336537.

[67] N. Duan, X. Wang, N. Li, H. D. Liu, and J. C. Campbell, "Thermal analysis of high-power InGaAs-InP photodiodes," IEEE J. Quantum Electron., vol. 42, no. 12, pp. 1255-1258, Dec. 2006, doi: 10.1109/JQE. 2006.883498.

[68] A. Beling, X. Xie, and J. C. Campbell, "High-power, high-linearity photodiodes," Optica, vol. 3, no. 3, p. 328, Mar. 2016, doi: 10.1364/optica.3.000328

[69] G. Lucovsky, M. E. Lasser, and R. B. Emmons, "Coherent Light Detection in Solid-State Photodiodes," Proc. IEEE, vol. 51, no. 1, pp. 166-172, 1963, doi: 10.1109/PROC.1963.1675.

[70] R. P. Riesz, "High speed semiconductor photodiodes," Rev. Sci. Instrum., vol. 33, no. 9, pp. 994-998, Sep. 1962, doi: $10.1063 / 1.1718049$.

[71] M. Natrella et al., "Accurate equivalent circuit model for millimetre-wave UTC photodiodes," Opt. Express, vol. 24, no. 5, p. 4698, Mar. 2016, doi: 10.1364/OE.24.004698.

[72] M. Natrella et al., "Modelling and measurement of the absolute level of power radiated by antenna integrated THz UTC photodiodes," Opt. Express, vol. 24, no. 11, p. 11793, May 2016, doi: 10.1364/OE.24.011793.

[73] C. C. Renaud, M. Natrella, C. Graham, J. Seddon, F. Van Dijk, and A. J. Seeds, "Antenna integrated THz uni-traveling carrier photodiodes," IEEE J. Sel. Top. Quantum Electron., vol. 24, no. 2, Mar. 2018, doi: 10.1109/JSTQE.2017.2725444.

[74] D. Rutledge, D. Neikirk, and D. Kasilingam, "INTEGRATEDCIRCUIT ANTENNAS.," Infrared Millim. waves, vol. 10, 1983.

[75] B. Sartorius et al., "Continuous wave terahertz systems exploiting $1.5 \mu \mathrm{m}$ telecom technologies," Opt. Express, vol. 17, no. 17, p. 15001, Aug. 2009, doi: 10.1364/oe.17.015001.

[76] A. V. Boriskin, A. I. Nosich, S. V. Boriskina, T. M. Benson, P. Sewell, and A. Altintas, "Lens or resonator? Electromagnetic behavior of an extended hemielliptic lens for a sub-millimeter-wave receiver," Microw. Opt. Technol. Lett., vol. 43, no. 6, pp. 515-518, Dec. 2004, doi: 10.1002/mop.20520.

[77] S. Nellen et al., "Experimental Comparison of UTC- and PINPhotodiodes for Continuous-Wave Terahertz Generation," $J$. Infrared, Millimeter, Terahertz Waves, vol. 41, no. 4, pp. 343-354, Apr. 2020, doi: 10.1007/s10762-019-00638-5.

[78] TOPTICA Photonics, "TeraScan Frequency-Domain Terahertz Platform," 2021. https://www.toptica.com/products/terahertzsystems/frequency-domain/terascan/ (accessed Jul. 20, 2021).

[79] H. Ibach and H. Luth, "Thermal Properties," in Solid-State Physics: An Introduction to Principles of Materials Science, 4th ed., H. Ibach 
and H. Luth, Eds. Berlin, Heidelberg: Springer Berlin Heidelberg, 2009, pp. 113-134.

[80] U. Gliese, K. Colladay, A. S. Hastings, D. A. Tulchinsky, V. J. Urick, and K. J. Williams, " $53.5 \%$ photodiode RF power conversion efficiency," in Optics InfoBase Conference Papers, Mar. 2010, p. PDPA7, doi: 10.1364/ofc.2010.pdpa7.

[81] K. J. Williams and R. D. Esman, "Design considerations for highcurrent photodetectors," J. Light. Technol., vol. 17, no. 8, pp. 14431454, Aug. 1999, doi: 10.1109/50.779167.

[82] H. Chen, A. Beling, H. Pan, and J. C. Campbell, "A Method to Estimate the Junction Temperature of Photodetectors Operating at High Photocurrent," IEEE J. Quantum Electron., vol. 45, no. 12, pp. 1537-1541, 2009, doi: 10.1109/JQE.2009.2023609.

[83] T. Ishibashi, T. Furuta, H. Fushimi, and H. Ito, "Photoresponse characteristics of uni-traveling-carrier photodiodes," in Physics and Simulation of Optoelectronic Devices IX, Jul. 2001, vol. 4283, no. 9 , p. 469, doi: 10.1117/12.432597.

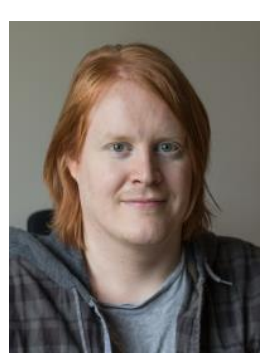

James Seddon received BSc degree in Chemistry from the University of Plymouth, MSc degree in Nanoscience and Technology from the University of Sheffield, and MRes and PhD degrees in Integrated Photonic and Electronic Systems from University College London. He is currently a Research Associate in the Ultra-Fast Photonics group at UCL. His research interested are terahertz spectroscopy and sensing and terahertz metamaterials. His work has generated 13 publications in peer reviewed journals and international conferences and 1 patent.

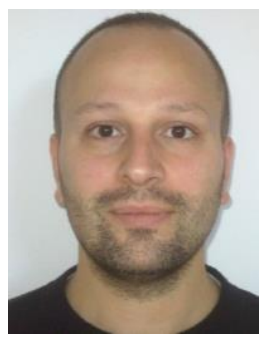

Michele Natrella Dr Michele Natrella received the five-year Laurea degree in electronic engineering from Politecnico di Bari, Italy, in 2007. He spent a year in industry working as a design engineer within the electronic security systems sector. He was then employed as an R\&D engineer at the applied research organisation CETMA, Brindisi, Italy. Here he spent 3 years, conducting research on wireless communications, laser range finders and software development. He moved to academia in October 2010, when he joined the Ultra-Fast Photonics Group at University College London (UCL), UK, employed as a Marie Curie researcher, to work on the development of photonic terahertz emitters and receivers. This work led to the award of a PhD in Photonics in 2015. Dr Natrella continued to work at UCL as a Senior Research Associate until 2017, when he moved to the Defence Industry. Dr Natrella is currently the head of the Antenna Team and a Lead Photonics Engineer at Leonardo-UK, Airborne \& Space Systems, in Luton and still collaborates with the Photonics Group at UCL, where he is an Honorary Senior Research Associate. His research in Academia has led to 37 publications in peer reviewed journals and international conferences.

Xiaoli Lin received BSc. Degree in Optics from Shandong University, Ji'nan, China and MRes degree in Integrated Photonic and Electronic Systems from University College
London. She is currently $\mathrm{PhD}$ student in the Ultra-Fast Photonics group at UCL. Her research interests are UniTravelling Carrier photodiode, terahertz communication and silicon photonics.

Chris Graham received BEng. degree from University of Essex. Joined Ultra-fast photonics group at Department of Electronic and Electrical Engineering at UCL in 2006. Researched ultrafast photonic switches for sampling applications, obtaining a $\mathrm{PhD}$ in 2011. Has worked as a Research Associate in the Photonics Group for the last 7 years working in the fields of Uni Travelling Photodiode design fabrication and evaluation; Photonic Integrated Circuit (PIC) packaging and ultrafast photoconductors. His work has led to over 20 publications in peer reviewed journals and international conferences, and 1 patent.

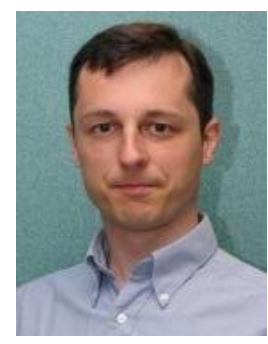

Cyril C. Renaud (M'08, SM'12) Prof Cyril Renaud received the degree of engineering from the Ecole Supérieure d'Optique, Orsay, France, and the Diplôme d'Etudes Approfondies (D.E.A.) in Optics and Photonics from the University Paris XI, Orsay, France, in 1996. He spent one year as a project engineer with Sfim-ODS, working on the development of microchips lasers and portable range finders. He, then, joined the Optoelectronics Research Centre, University of Southampton, Southampton UK, in 1998, to work on diode pumped high-power ytterbium-doped fibre-lasers, with particular interest on Q-switched system and 980-nm generation. This work led to the award of a $\mathrm{PhD}$ in 2001. He is currently a Professor of Photonics at University College London, and the Programme director for the UCL/Cambridge Doctoral Training Centre in Connected Electronic and Photonic Systems. His work has led to over 200 publications in peer reviewed journals and international conferences, and 3 patents.

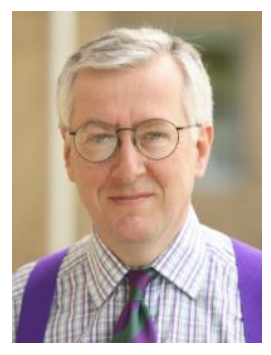

Alwyn J. Seeds received the B.Sc, Ph.D. and D.Sc. degrees from the University of London. From 1980 to 1983 he was a Staff Member at Lincoln Laboratory, Massachusetts Institute of Technology, where he worked on GaAs monolithic millimetre-wave integrated circuits for use in phased-array radar. Following three years as lecturer in telecommunications at Queen Mary College, University of London he moved to University College London in 1986, where he is now Professor of Opto-electronics and Head of the Photonics Group. He has published over 400 papers on microwave and opto-electronic devices and their systems applications. His current research interests include photonic integration, semiconductor opto-electronic devices, wireless and optical communication systems.

Professor Seeds is a Fellow of the Royal Academy of Engineering (UK) and an IEEE Life Fellow (USA). He has been 
a Member of the Board of Governors and Vice-President for Technical Affairs of the IEEE Photonics Society (USA). He has served on the programme committees for many international conferences. He is a co-founder of Zinwave, a manufacturer of wireless over fibre systems. He was awarded the Gabor Medal and Prize of the Institute of Physics in 2012 and the Distinguished Educator Award of the IEEE Microwave Theory and Techniques Society in 2018. 